\title{
LncRNA SNHG20 promotes tumorigenesis and cancer stemness in glioblastoma via activating PI3K/Akt/mTOR signaling pathway
}

\author{
X. F. GAO ${ }^{1}$, H. Q. $\mathrm{HE}^{2}$, X. B. ZHU' ${ }^{1}$, S. L. XIE 3 , Y. CAO ${ }^{4, *}$ \\ ${ }^{1}$ Department of Neurosurgery, The First Hospital of Jilin University, Jilin, China; ${ }^{2}$ Intensive Medicine Department, The First Hospital of Jilin \\ University, Jilin, China; ${ }^{3}$ Department of Hepatobiliary Surgery, The First Hospital of Jilin University, Jilin, China; ${ }^{4}$ Clinical Laboratory, The First \\ Hospital of Jilin University, Jilin, China
}

*Correspondence: yangao113_CCCC@163.com

Received August 29, 2018 / Accepted January 8, 2019

\begin{abstract}
Long noncoding RNAs (lncRNAs) play crucial roles in the development of human cancers. LncRNA small nucleolar RNA host gene 20 (SNHG20) has been reported to be an oncogene in several cancers, whereas the specific role of SNHG20 in glioblastoma is unclear. In this study, we found that SNHG20 was significantly upregulated in glioblastoma tissues and cell lines. Survival analysis suggested that high expression of SNHG20 indicated the low overall survival rate of glioblastoma patients. Subsequently, gain or loss-of-function assays were carried out to examine the effect of SNHG20 on glioblastoma cell proliferation and apoptosis. We found that SNHG20 knockdown obviously suppressed cell proliferation, increased cell apoptosis and impaired stem properties, while SNHG20 overexpression led to the opposite results. In vivo experiment demonstrated that knockdown of SNHG20 efficiently suppressed cell growth in vivo. Furthermore, western blotting demonstrated that the PI3K/Akt/mTOR signaling pathway was activated by SNHG20 in glioblastoma cells. At last, rescue assays validated that PI3K/Akt/mTOR signaling pathway was involved in the glioblastoma progression mediated by SNHG20. Taken together, this study revealed that SNHG20 regulated PI3K/Akt/mTOR signaling pathway to promote tumorigenesis and stemness of glioblastoma.
\end{abstract}

Key words: SNHG20, proliferation, PI3K/Akt/mTOR signaling pathway, glioblastoma

There are several main subtypes of glioma, such as astrocytic tumors, oligodendrogliomas, ependymomas, and mixed gliomas. Glioblastoma (GBM) is an astrocytic tumor that accounts for more than $80 \%$ of malignant brain tumors [1]. GBM belongs to grade IV gliomas with extremely poor prognosis [2]. In recent years, researches about the GBM have been increasing $[3,4]$. Therefore, it is urgent to find novel effective targets for the diagnosis and treatment of glioblastoma.

Long noncoding RNAs (lncRNAs) were certified as a class of endogenous transcripts which are longer than 200 nucleotides and cannot code proteins [5]. LncRNAs participate in various biological processes, such as cell proliferation, invasion and migration [6-8]. According to previous studies, the abnormal expression of lncRNAs can modulate cell growth and metastasis in glioblastoma [9-11]. In addition, lncRNAs can maintain the stem cell properties in glioblastoma [12]. LncRNA SNHG20 has been reported to be highly expressed in breast cancer [13] and cervical cancer [14]. In addition, dysregulation of SNHG20 is correlated with the poor prognosis of colorectal cancer [15]. However, to our knowledge, the specific function of SNHG20 in glioblastoma is still unknown. Therefore, this study focused on investigating the role of lncRNA SNHG20 in tumorigenesis and cancer stemness of glioblastoma.

In this study, we tested the expression of SNHG20 in glioblastoma tissues and cell lines. The potential effect of SNHG20 on the prognosis of patients with glioblastoma was analyzed. Gain-of function assays and loss-of function assays were conducted in two different glioblastoma cell lines to determine the function of SNHG20. The association between SNHG20 and PI3K/Akt/mTOR signaling pathway was analyzed and identified. Finally, rescue assays were carried out to demonstrate the involvement of PI3K/ Akt/mTOR signaling pathway in SNHG20-mediated glioblastoma progression. In summary, this study revealed the function and potential mechanism of SNHG20 in glioblastoma. 


\section{Material and methods}

Tissues samples. 78 pairs of human glioblastoma tissues and adjacent tissues were obtained from patients with glioblastoma at The First Hospital of Jilin University. This study was approved by the ethics committee of The First Hospital of Jilin University. All patients signed informed consent.

Cell culture. Four glioblastoma cell lines (U87MG, U343, U251, LN215) and one normal human astrocytes cell line (HA) were bought from American Type Culture Collection (ATCC, Manassas, VA, USA). All cells were incubated in Dulbecco's modified Eagle's medium (DMEM) (Invitrogen, Carlsbad, CA, USA), which contained 10\% FBS (Gibco, Grand Island, NY, USA), $100 \mathrm{U} / \mathrm{ml}$ penicillin, as well as $100 \mu \mathrm{g} / \mathrm{ml}$ streptomycin. All cell lines were cultured in humidified chamber at $37^{\circ} \mathrm{C}$ containing $5 \% \mathrm{CO}_{2}$.

Cell treatment. $3 \mu \mathrm{g} / \mathrm{ml} \mathrm{IGF-1} \mathrm{(Clontech,} \mathrm{Mountain}$ View, CA, USA) and 0.5 $\mu$ M GDC-0941 (Calbiochem, San Diego, CA, USA) were used to treat U251 and LN215 cells. Cells were plated into six-well plates containing DMEM and PBS (Invitrogen, USA). Next, cells were treated with IGF-1 or GDC-0941 for $24 \mathrm{~h}$. Cells in culture medium without IGF-1 and GDC-0941 were used as a control. At last, cells were harvested for subsequent experiments. For rescue assays, cells were transfected with sh-SNHG20 for 48 h, followed by treatment with IGF-1 or GDC- 0941 for $24 \mathrm{~h}$.

Cell transfection. U251 and LN215 cell lines were plated into six-well plates and cultured routinely in an incubator with $5 \% \mathrm{CO}_{2}$ at $37^{\circ} \mathrm{C}$. After reaching $80-90 \%$ cell confluence, the cell culture was terminated. To knockdown SNHG20 expression, cells were transfected with the short hairpin RNA targeting SNHG20 (RiboBio, Guangzhou, China, termed sh-SNHG20) and negative control (sh-NC, RiboBio). To overexpress SNHG20 expression, pcDNA3.1 vector specific to SNHG20 (GenePharma, Shanghai, China, termed SNHG20) was constructed and transfected into U251 and LN215 cells. An empty pcDNA3.1 vector (GenePharma) was used as a negative control (NC). Lipofectamine2000 reagent (Invitrogen, Carlsbad, CA, USA) was used for cell transfection based on the supplier's recommendation. Transfection efficiency was measured and determined $48 \mathrm{~h}$ post-transcription.

RNA isolation and qRT-PCR. At first, the total RNA was isolated from glioblastoma tissues and cell lines using TRIzol reagent (Invitrogen, Carlsbad, CA, USA) in line with the supplier's recommendation. The complementary DNA (cDNA) was generated using the PrimeScript RT reagent Kit (Thermo Scientific, Glen Brunie, MA, USA). Reverse transcription was performed under the conditions of $37^{\circ} \mathrm{C}$ for $15 \mathrm{~min}$ and $85^{\circ} \mathrm{C}$ for $5 \mathrm{~s}$. Quantitative real-time PCR (qRT-PCR) was conducted by using a SYBR Premix EX Taq ${ }^{\text {ma }}$ Kit (Takara, Dalian, China) and ABI 7500 Real-Time PCR system (Applied Biosystems, Foster City, USA). The parameters of PCR amplification reaction were: $95^{\circ} \mathrm{C}$ for $15 \mathrm{~s}, 40$ cycles of $95^{\circ} \mathrm{C}$ for $5 \mathrm{~s}$ and $60^{\circ} \mathrm{C}$ for $30 \mathrm{~s}$. GAPDH was utilized as an internal control. Fold changes were calculated using a relative quantification $\left(2^{-\triangle \Delta C t}\right)$ method. Primer sequences: SNHG20 F, 5'-ATGGCTATAAATAGATACACGC-3' and R, 5'-GGTACAAACAGGGAGGGA-3'; CD44 F, 5'-GTCAAGTGAGCTGTCTGCGA-3' and R, 5'-TCAAGCTTCCACAGCGCTAA-3'; CD133 F, 5'-GGGTCTTGGGAACGAGTCTG-3' and R, 5'-TCCTCTTTGTTGTCCGGTCG-3'; Oct-4 F, 5'GGACCTGGCTAAGCTTCCAA-3' and R, 5'-AGGTGACCACTTCCCCATCA-3'; GAPDH F, 5'-ACAGTCAGCCGCATCTTCT-3' and R, 5'-GACAAGCTTCCCGTTCTCAG-3'.

MTT analysis. Cell proliferation was measured by methylthiazoletetrazolium (MTT) assay. U251 and LN215 cells $\left(4 \times 10^{3}\right.$ cells/per well) were cultured in 96-well plates (Sigma-Aldrich; Merck KGaA, St. Louis, USA). $100 \mu \mathrm{l}$ DMEM containing $10 \%$ FBS was applied to incubate cells for $72 \mathrm{~h}$ at $37^{\circ} \mathrm{C}$ with $5 \% \mathrm{CO}_{2}$. After incubation, cells of each well were treated with $10 \mu \mathrm{l}$ MTT solution $(5 \mathrm{mg} / \mathrm{mL}$, Sigma, St. Louis, USA) for various time points $(24,48,72,96 \mathrm{~h})$. After $2 \mathrm{~h}$ incubation, $150 \mu \mathrm{l}$ DMSO (Sigma-Aldrich and Merck KGaA, Darmstadt, Germany) was added into the reaction to solubilize the MTT crystal. At last, the absorbance at $490 \mathrm{~nm}$ was measured using a microplate reader (Thermo, Rockford, USA).

Colony formation assay. $48 \mathrm{~h}$ post transfection, $\mathrm{U} 251$ and LN215 cells (at a density of $1 \times 10^{3}$ cells/well) were seeded onto six-well plates and cultured at $37^{\circ} \mathrm{C}$ in a humid incubator containing $5 \% \mathrm{CO}_{2}$. Medium was replaced every third day until incubation terminated. After two weeks, the colonies were washed 3 times with PBS (Invitrogen, CA, USA) and then fixed with $4 \%$ formaldehyde for $30 \mathrm{~min}$. After fixation, cells were stained with $0.1 \%$ crystal violet solution for half an hour. At last, the number of colonies was counted manually.

Flow cytometry analysis. Glioblastoma cells (U251 and LN215) were collected $48 \mathrm{~h}$ post-transfection and washed 2 times with cold PBS before fixing with $70 \%$ cold ethanol at $4{ }^{\circ} \mathrm{C}$ overnight. Subsequently, RNase was added and incubated with cells at $37^{\circ} \mathrm{C}$ for half an hour. For cell cycle analysis, cell lines were stained with Propidium Iodide (PI, Sigma-Aldrich; San Francisco, CA, USA) in the dark. The cycle distributions of cells at G0/G1, S, and G2/M phases were examined using FACScan flow cytometer (BD Biosciences, San Jose, CA, USA) and FlowJo software (Treestar, Inc., Ashland, OR, USA) in accordance with the user guide. As for the cell apoptosis analysis, cell lines were stained with Annexin V-PE and 7-AAD (Sigma-Aldrich) in the dark. After incubation for an hour at room temperature, the cell apoptosis rate was detected using the FACScan flow cytometer and FlowJo software.

In vivo assay. To conduct in vivo tumorigenesis assay, $\mathrm{BALB} / \mathrm{c}$ male nude mice, aged 5 weeks and weighed $18-20 \mathrm{~g}$, were purchased from National Laboratory Animal Center (Beijing, China) and kept under specific pathogen-free condition. Animal study was undertaken strictly in line with the protocol approved by the Administrative Panel on 
A

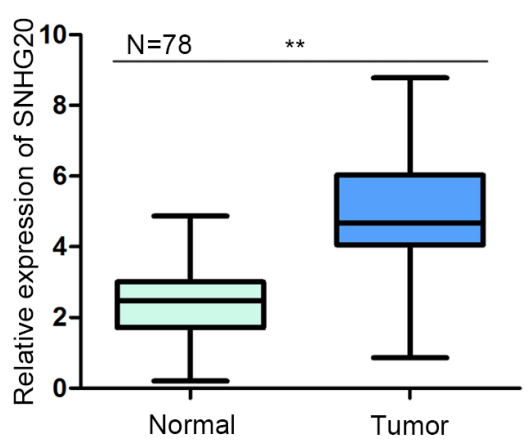

B

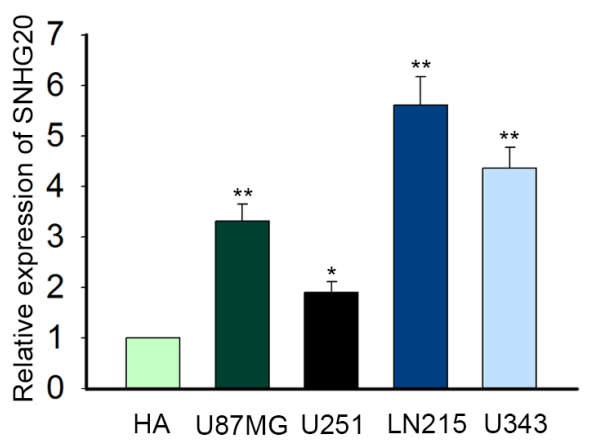

C

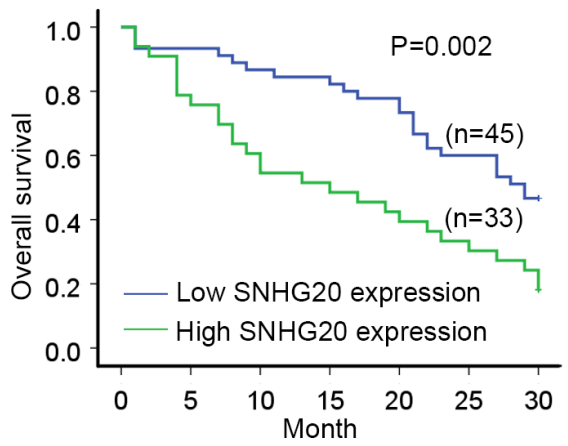

Figure 1. High expression of SNHG20 predicted poor prognosis of patients with glioblastoma. A) The relative expression level of SNHG20 in 78 pairs of glioblastoma tissues and adjacent normal tissues was measured by qRT-PCR assay. B) qRT-PCR assay was conducted to detect the expression level of SNHG20 in four glioblastoma cell lines (U87MG, U343, U251, LN215) and one normal human astrocyte (HA). C) The correlation between SNHG20 expression and overall survival rate was analyzed by Kaplan-Meier method and $\log \operatorname{rank}$ test. ${ }^{*} \mathrm{p}<0.05,{ }^{* *} \mathrm{p}<0.01$.

Laboratory Animal Care of the First Hospital of Jilin University. $2 \times 10^{6}$ cells transfected with sh-SNHG20 or sh-NC were suspended in $0.4 \mathrm{ml}$ PBS and subcutaneously injected into the dorsal right flank of mice ( $\mathrm{n}=3$ per group). Tumor volumes were examined every 5 days. Four weeks later, nude mice were sacrificed. Tumor volume was calculated as follows: volume $\left(\mathrm{mm}^{3}\right)=(\text { shortest diameter })^{2} \times($ longest diameter $) \times$ 0.5. After excising tumors, the tumor weight was recorded.

Sphere-formation assay. The cultured cells were recovered and seeded into six-well plates (Corning, Kraemer, CA) at a density of $5 \times 10^{4}$ cells per well. Then, cells were re-suspended in $2 \mathrm{ml}$ serum-free DMEM in the presence of $20 \mathrm{mg} / \mathrm{l} \mathrm{EGF}$, $20 \mathrm{mg} / \mathrm{l} \mathrm{hFGF,} 4 \mathrm{U} / \mathrm{l}$ insulin along with $100 \mathrm{U} / \mathrm{ml}$ mixture of penicillin and streptomycin. Cells were incubated at $37^{\circ} \mathrm{C}$ in a humidified atmosphere with $5 \% \mathrm{CO}_{2}$. Ten days later, the diameters of cell spheres were assessed. The number of spheroids with a diameter $>100 \mu \mathrm{m}$ was defined as primary spheres and calculated under a stereomicroscope (Olympus, Tokyo, Japan). The spheres were reaped by centrifugation, mixed with $0.05 \%$ trypsin $/ 0.02 \%$ ethylendiaminetetraacetic acid (EDTA) and dissociated into the single cell suspension. The primary spheres were passaged. Dissociated cells were seeded into six-well plates $\left(10^{4} \mathrm{cells} / \mathrm{ml}\right)$ in a serum-free medium and cultured for further ten days to acquire the secondary spheres.

Western blotting. Transfected cells were plated into six-well plates and lysed using RIPA buffer (Beyotime Institute of Biotechnology, Shanghai, China) on ice. BCA protein assay kit (Beyotime, China) was utilized to measure the protein concentration. Each sample was subjected to SDS-PAGE (Thermo, Rockford, USA) and then transferred to PVDF membranes (Millipore, Bedford, MA, USA). After incubating on ice overnight, the membranes were blocked by Tween-Tris-buffered saline (TTBS) containing 5\% non-fat milk at room temperature for $2 \mathrm{~h}$. Primary antibodies specific to Cyclin D1 (ab16663), CDK4 (ab108357), total caspase-3 (ab13585), total caspase-9 (ab32539), CD44 (ab157107),
CD133 (ab19898), Oct-4 (ab18976), PI3K (ab32089), p-PI3K (ab182651), Akt (ab179463), p-Akt (ab81283), mTOR (ab2732), p-mTOR (ab109268) and GAPDH (ab9485) were purchased from Abcam (Cambridge, UK). Anti-cleaved caspase-3 (\#9661) and anti-cleaved caspase-9 (\#9505) were bought from Cell Signaling Technology (Danvers, MA, USA). All primary antibodies were diluted at 1:1000 and incubated with membranes at $4{ }^{\circ} \mathrm{C}$ overnight. Subsequently, membranes were washed with TTBS at least three times and incubated with secondary antibody (1:2000) at room temperature for $2 \mathrm{~h}$. The housekeeping gene GAPDH was used as an internal control. The blots were visualized with enhanced chemiluminescence kit (ECL, Millipore, USA).

Statistical analysis. Statistical analyses were performed using SPSS19.0 statistical software (SPSS, Chicago, IL, USA). Data were acquired from more than three independent replicates and presented as the mean \pm standard error of the mean (SEM). The differences of groups were measured by Student's t-test, one-way analysis of variance (ANOVA) or $\chi^{2}$ test. Survival curve was generated using the Kaplan-Meier method and assessed by the log-rank test. A p-value less than 0.05 indicated the statistical significance.

\section{Results}

High expression of SNHG20 predicted poor prognosis of patients with glioblastoma. To investigate the specific role of SNHG20 in glioblastoma, we first detected the expression level of SNHG20 in glioblastoma tissues by qRT-PCR assay. We found that SNHG20 was highly expressed in 78 pairs of glioblastoma tissues compared with adjacent normal tissues (Figure 1A). Moreover, SNHG20 was upregulated in four glioblastoma cell lines (U87MG, U343, U251, LN215) in comparison with normal human astrocyte (Figure 1B). Subsequently, we separated 78 pairs of glioblastoma tissues into two groups in accordance with the mean expression of SNHG20. The association between SNHG20 expression and 
the clinicopathological features of glioblastoma patients. The expression of SNHG20 was related to clinical stage and tumor size (Table 1). Kaplan-Meier analysis suggested that patients with high level of SNHG20 had a lower overall survival rate than those with low level of SNHG20 (Figure 1C). All these results suggested the possible involvement of SNHG20 in the progression of glioblastoma.

SNHG20 accelerated cell proliferation and inhibited cell apoptosis in glioblastoma. To explore the role of SNHG20 in glioblastoma cells, gain or loss-of function assays were carried out in LN215 and U251 cells. SNHG20 was overexpressed or silenced in LN215 and U251 cells, respec- tively (Figures 2A, 3A). According to the results of MTT assay and colony formation assays, knockdown of SNHG20 remarkably inhibited the proliferative ability of LN215 and U251 cells (Figures 2B-C, 3B-C). However, SNHG20 overexpression led to the opposite results. Flow cytometry analysis revealed that knockdown of SNHG20 significantly arrested cell cycle at G0/G1 phase and promoted cell apoptosis (Figures 2D-E, 3D-E). Whereas the opposite results were observed in response to SNHG20 overexpression. Furthermore, we analyzed the effect of SNHG20 overexpression or knockdown on the levels of proteins correlated with cell cycle or apoptosis. Protein levels of Cyclin D1 and CDK4
A

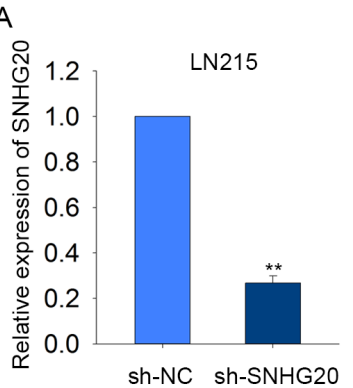

C
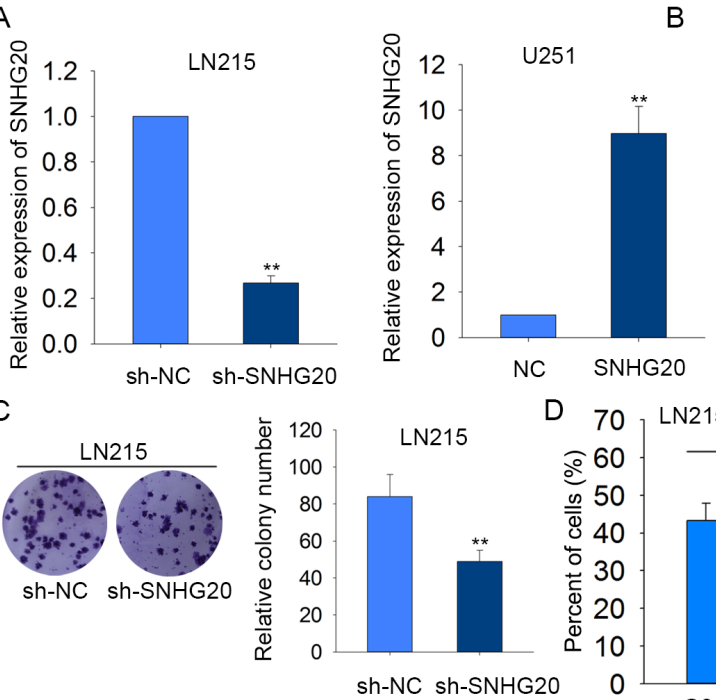

D $70, \mathrm{LN} 215$

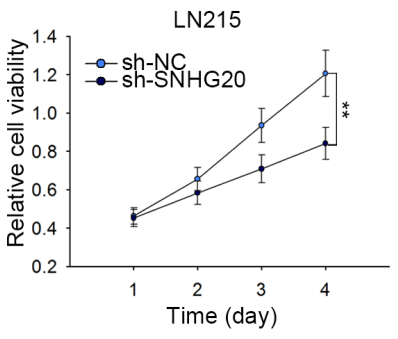

F

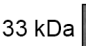

$34 \mathrm{kDa}$

$37 \mathrm{kDa}$
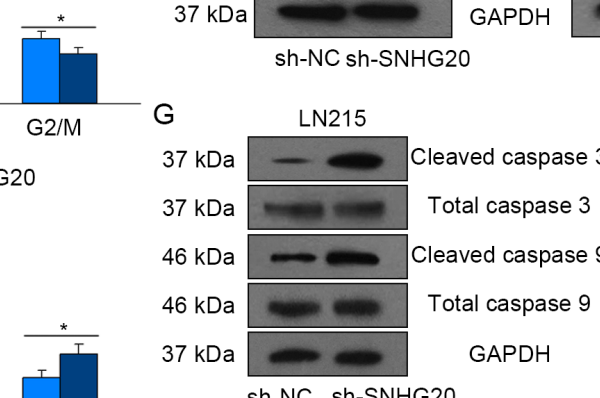

E

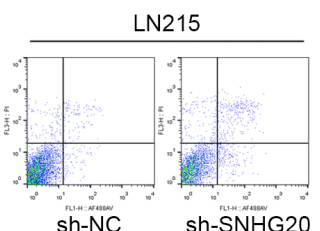

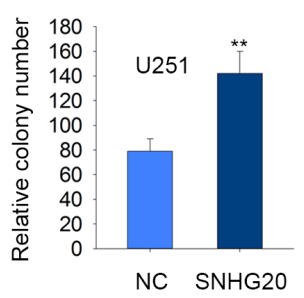

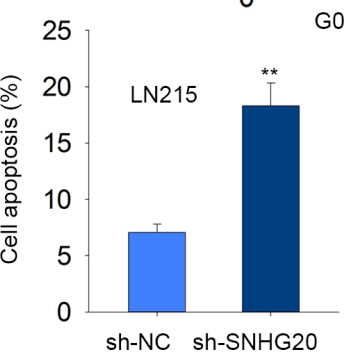

sh-NC sh-SNHG20

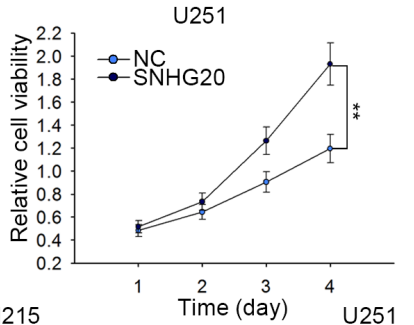

LN215

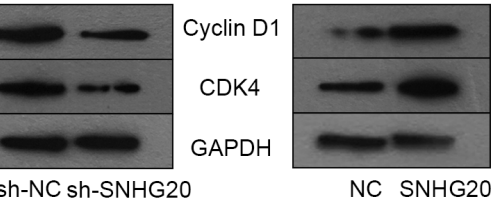

$\mathrm{U} 251$
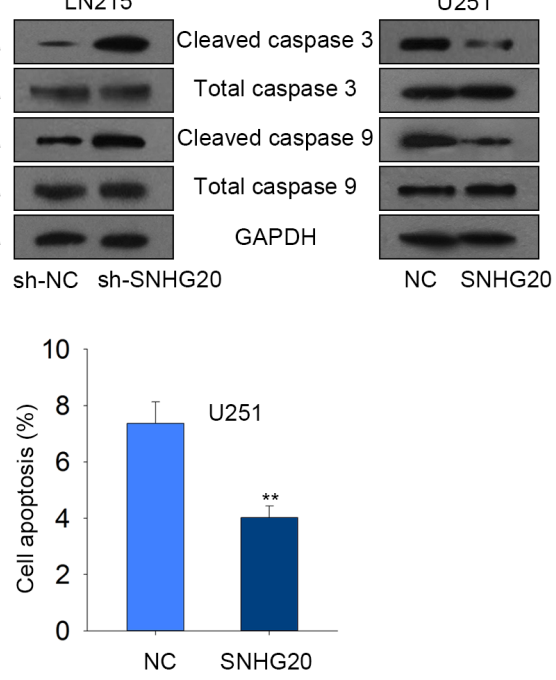

Figure 2. SNHG20 accelerated cell proliferation and inhibited cell apoptosis in glioblastoma. A) LIN215 cell was treated with sh-SNHG20 or sh-NC, while U251 cells were transfected with SNHG20 expression vector and empty vector (NC). Transfection efficiency was determined by qRT-PCR assay $48 \mathrm{~h}$ post-transfection. B-C) MTT assay and colony formation assay were performed to analyze cell proliferation in LN215 cell transfected with shSNHG20 or U251 cell transfected with pcDNA-SNHG20. D-E) Cell cycle distribution and apoptosis were determined using flow cytometry analysis in LN215 cell transfected with sh-SNHG20 or U251 cell transfected with pcDNA-SNHG20. F) The protein levels of Cyclin D1 and CDK4 were measured in sh-SNHG20 group and pcDNA-SNHG20 group by western blotting. G) Western blotting examined the levels of apoptosis-related proteins in indicated cells. GAPDH was used as the internal control. ${ }^{\star} \mathrm{p}<0.05,{ }^{* *} \mathrm{p}<0.01$. 
were increased by SNHG20 knockdown, while decreased by SNHG20 overexpression (Figure 2F). In addition, SNHG20 knockdown increased the protein level of cleaved caspase 3 and cleaved caspase 9, while SNHG20 overexpression led to the opposite results (Figure 2G). These findings revealed that SNHG20 promotes cell proliferation and inhibits apoptosis in glioblastoma.

Knockdown of SNHG20 inhibited glioblastoma cell growth in vivo. In vivo experiment was conducted to determine the role of SNHG20 in the glioblastoma tumor growth. The tumor derived from LN215 cells transfected with sh-SNHG20 was smaller than that derived from LN215 cells transfected with sh-NC (Figure 4A). The same tendency was observed in tumor volume and tumor weight (Figures $4 \mathrm{~B}-\mathrm{C}$ ).

SNHG20 enhanced the stemness of glioblastoma cells. Previous studies revealed that $\operatorname{lncRNAs}$ could regulate cancer stemness in glioma [16]. In the current study, we investigated the role of SNHG20 in regulating the stemness of glioblastoma cells. The results of sphere forming assay indicated that knockdown of SNHG20 obviously impaired the ability of sphere formation of LN215 and U251 cells,
Table 1. Correlation between SNHG20 expression and clinical features of glioblastoma patients $(n=78)$.

\begin{tabular}{llcl}
\hline \multirow{2}{*}{ Parameters } & \multicolumn{2}{c}{ SNHG20 expression } & \multirow{2}{*}{ p-value } \\
\cline { 2 - 3 } & low & high & \\
\hline Age (years) & 32 & 22 & 0.804 \\
$\quad<60$ & 13 & 11 & \\
$\quad \geq 60$ & & & \\
Gender & 20 & 13 & 0.816 \\
$\quad$ Male & 25 & 20 & \\
Female & & & $0.021^{\star}$ \\
Stage & 28 & 11 & \\
$\quad<3$ & 17 & 22 & $0.005^{\star *}$ \\
$\quad \geq 3$ & & & \\
Tumor size & 29 & 10 & 0.638 \\
$<3$ cm & 16 & 23 & \\
$\quad \geq 3$ cm & & & \\
Tumor location & 27 & 11 & \\
A (Supratentorial) & 18 & & \\
B (Infratentorial) & & &
\end{tabular}

Low/high expression was obtained by the sample mean. Pearson $\chi^{2}$ test. ${ }^{\star} \mathrm{p}<0.05,{ }^{* *} \mathrm{p}<0.01$ were considered statistically significant.
A
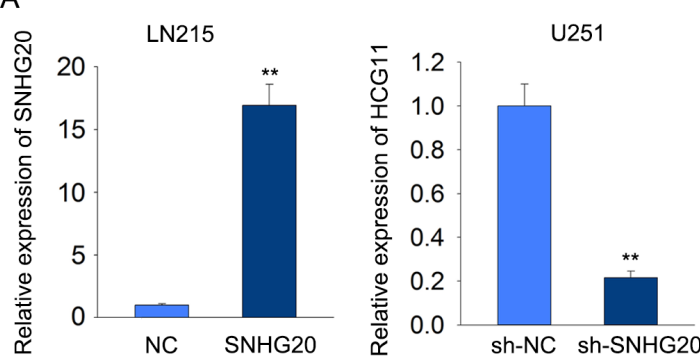

C

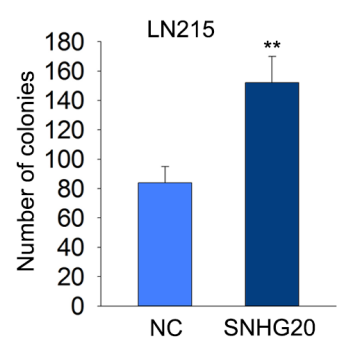

E

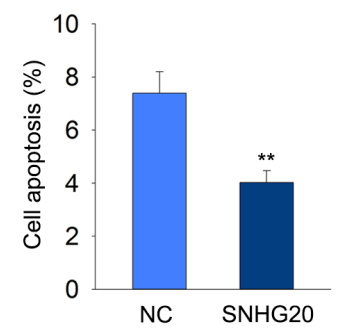

B
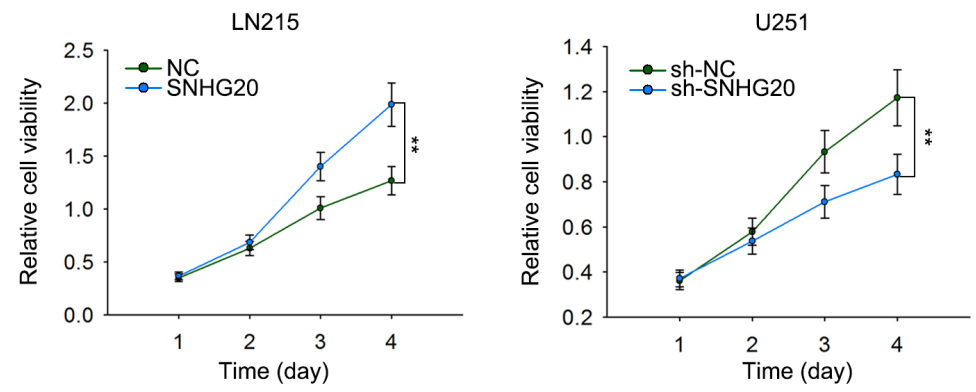

$\mathrm{D}$
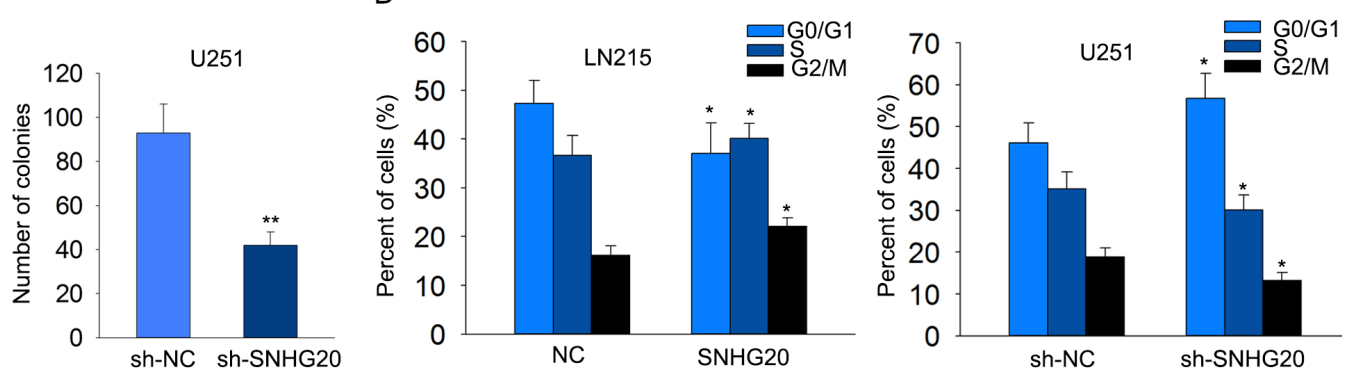

Figure 3. SNHG20 accelerated cell proliferation and inhibited cell apoptosis in glioblastoma. A) $48 \mathrm{~h}$ after transfection the efficiency was investigated in LN215 and U251 cells by qRT-PCR assay. B-C) MTT assay and colony formation assay were performed to analyze cell proliferation in indicated LN215 and U251 cells. D-E) Cell cycle distribution and apoptosis were determined using flow cytometry analysis in response to SNHG20 knockdown or overexpression. ${ }^{\star} \mathrm{p}<0.05,{ }^{* *} \mathrm{p}<0.01$. 
A

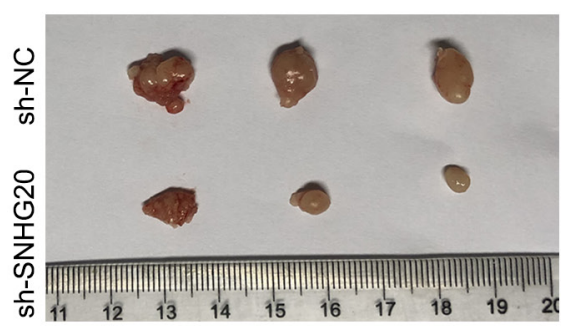

B

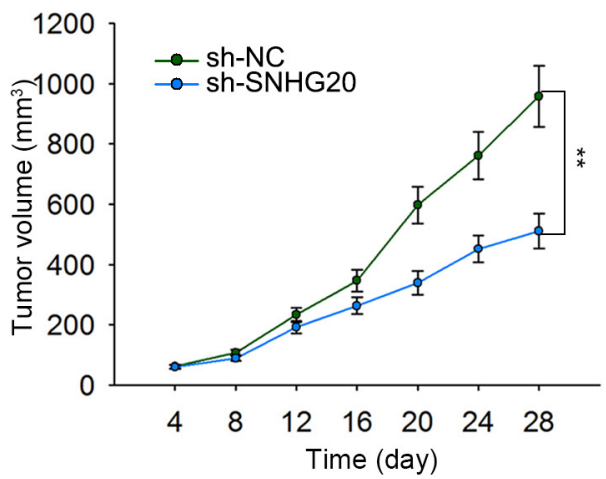

C

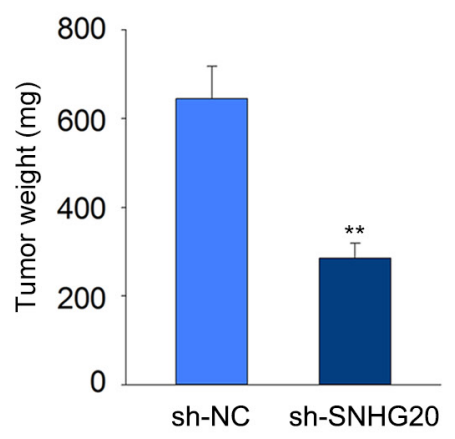

Figure 4. Knockdown of SNHG20 inhibited glioblastoma cell growth in vivo. A) Tumors derived from LN215 cells transfected with sh-SNHG20 or shNC are shown. B-C) Tumor volume and tumor weight in sh-SNHG20 group and sh-NC group were measured. ${ }^{* *} \mathrm{p}<0.01$.

but SNHG20 overexpression accelerated sphere formation (Figure 5A). To make further confirmation, we examined the expression level of surface antigens associated with cancer stemness (CD44, CD133) and stemness-associated gene (Oct-4). It was found that knockdown of SNHG20 obviously decreased the mRNA and protein levels of CD44, CD133 and Oct-4 (Figures 5B-C). On the contrary, SNHG20 overexpression exhibited opposite results. Therefore, we confirmed that SNHG20 enhanced the stemness of glioblastoma cells.

SNHG20 positively regulated the activity of PI3K/Akt/ mTOR signaling pathway. Increasing evidences indicate that PI3K/Akt signaling pathway played crucial role in lncRNAsmediated cell cycle progression and cell apoptosis [17-19]. Thus, we then explored whether SNHG20 could regulate PI3K/Akt signaling pathway in glioblastoma cells. Western blot analysis showed that the protein levels of phosphorylated PI3K, Akt and mTOR (p-PI3K, p-Akt and p-mTOR) were decreased by SNHG20 knockdown, while were increased by SNHG20 overexpression (Figure 6). There were no significant changes on the protein levels of PI3K, Akt and mTOR. These results showed that SNHG20 activated PI3K/Akt/ mTOR signaling pathway in glioblastoma cells.

PI3K/Akt/mTOR signaling pathway promoted cell proliferation and enhanced stemness in glioblastoma. To demonstrate the role of PI3K/Akt/mTOR signaling pathway in glioblastoma, we applied IGF-1 (PI3K signaling activator) and GDC-0941 (PI3K signaling inhibitor) to conduct functional assays. As presented in Figures 7A-B, the cell proliferation was promoted by IGF-1, while inhibited by GDC-0941. Furthermore, cell cycle progress was promoted by IGF-1, while inhibited by GDC-0941 (Figure 7C). Apoptosis was increased in LN215 cells treated with IGF-1, whereas apoptosis was decreased in U251 cells treated with GDC-0941 (Figure 7D). Additionally, the effect of IGF1 and GDC-0941 on stemness was analyzed. The sphere formation was enhanced by IGF-1, while decreased by GDC-0941
(Figure 7E). Consistently, the expression levels of CD33, CD133 and Oct- 4 were increased in LN215 cells treated with IGF-1, while decreased in U251 cells treated with GDC-0941 (Figure 7F).

SNHG20 promoted tumorigenesis and cancer stemness in glioblastoma via activating PI3K/Akt/mTOR signaling pathway. In order to confirm the effect of PI3K/Akt/mTOR signaling pathway on tumorigenesis and cancer stemness in glioblastoma, rescue assays were carried out. According to the results of MTT assay and colony formation assays, cell proliferation suppressed by SNHG20 knockdown was rescued by adding IGF-1 (Figures $8 \mathrm{~A}-\mathrm{B}$ ). However, cell proliferation enhanced by SNHG20 overexpression was obviously reversed by GDC-0941. Moreover, cell cycle arrest and apoptosis induced by SNHG20 knockdown were efficiently rescued by IGF-1. Whereas cell cycle and apoptosis caused by SNHG20 overexpression was recovered after addition of GDC-0941 (Figures 8C-D). Consistently, the stemness of glioblastoma cells suppressed by sh-SNHG20 was recovered by treating with IGF-1, while the enhanced stemness in SNHG20-overexpressed U251 cells was partially reversed by GDC-0941 (Figures 8E-F). All these results suggested that SNHG20 promotes tumorigenesis and cancer stemness in glioblastoma via activating PI3K/Akt/mTOR signaling pathway.

\section{Discussion}

Long non-coding RNAs were newly identified modulators in human diseases [20]. Previous reporters showed that lncRNA played crucial roles in regulating numerous cellular processes $[21,22]$. There are some reports revealing the role of $\operatorname{lncRNAs}$ in glioblastoma. For instance, lncRNA HOTAIR accelerated glioblastoma cell proliferation and migration via targeting NLK (Nemo-like kinase) [23]. LncRNA CRNDE promoted the malignant phenotypes of glioblastoma via P70S6K-mediated mTOR signaling pathway [24]. Up to 
A
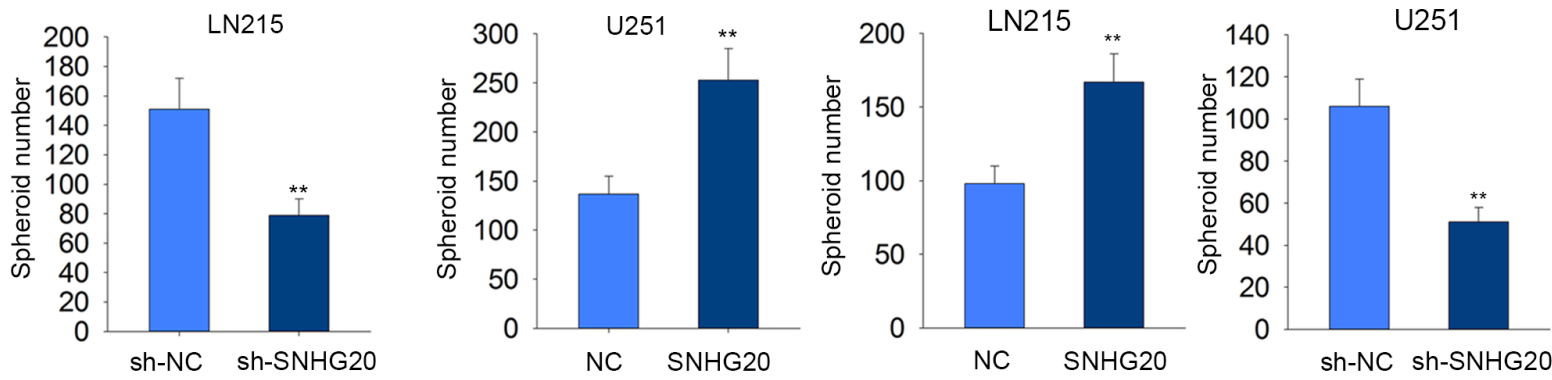

B
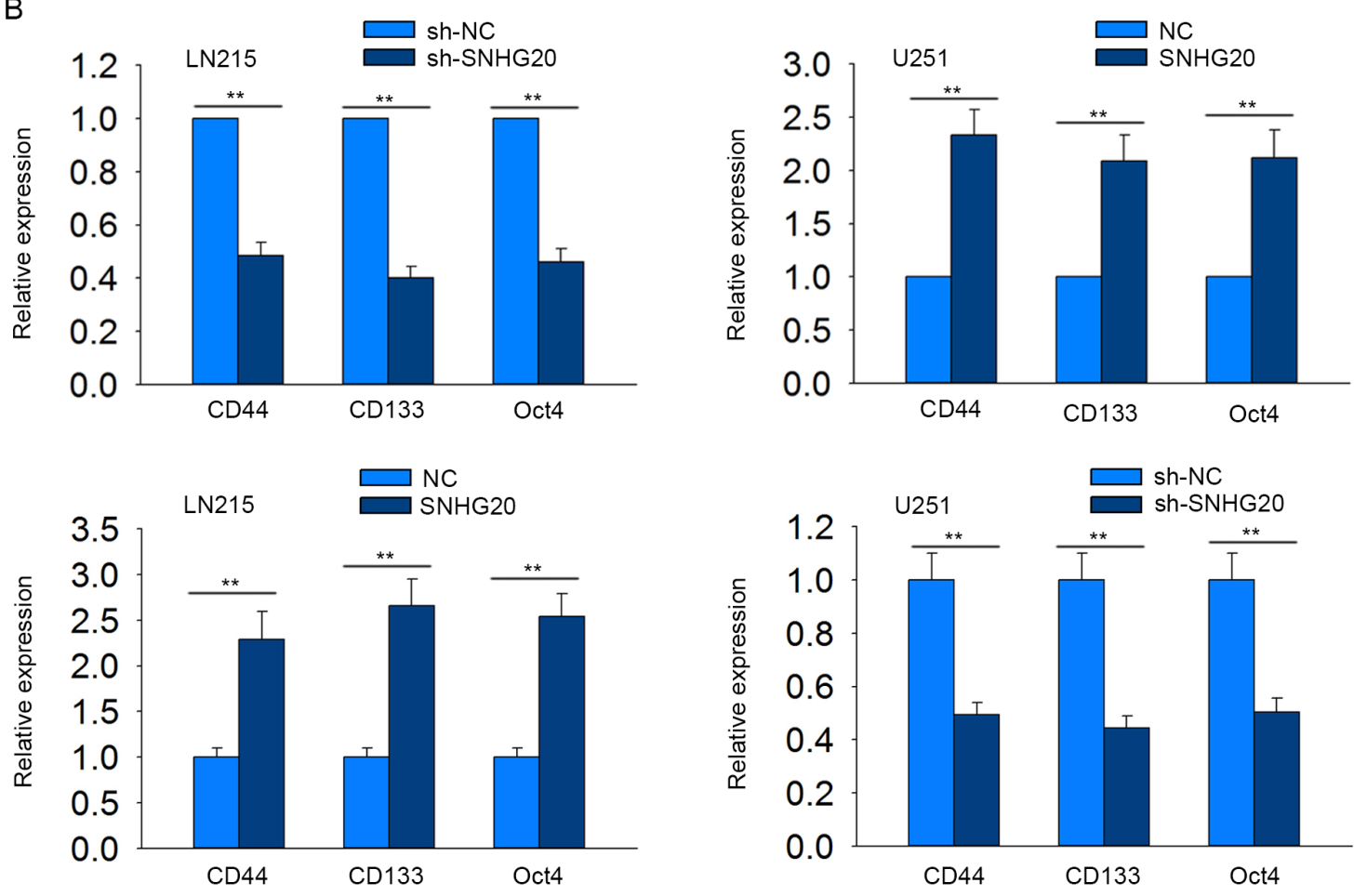

C

LN215

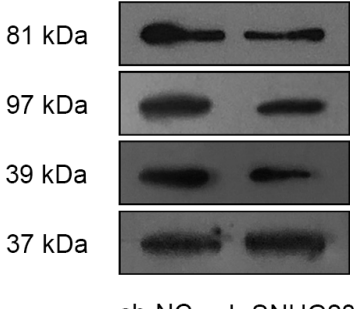

sh-NC sh-SNHG2O
U251

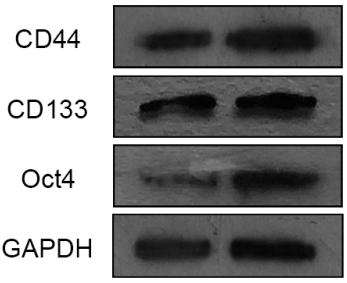

NC SNHG2O

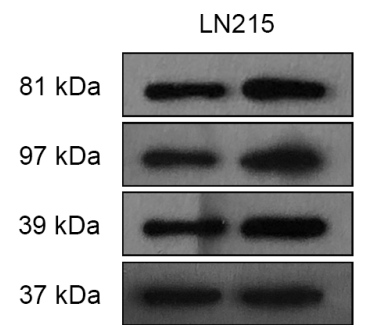

NC SNHG2O

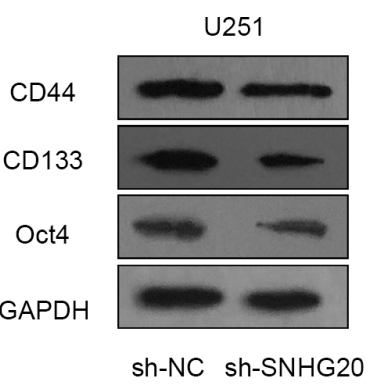

Figure 5. SNHG20 enhanced the stemness of glioblastoma cells. A) Sphere formation assays revealed the spheroid number in LN215 and U251 cells after transfection. B-C) The mRNA level and protein level of surface antigens associated with cancer stem cells and stemness-associated gene (CD44, CD133, Oct-4) were assessed in indicated cells by qRT-PCR assay and western blot assay. ${ }^{* *} \mathbf{p}<0.01$.

now, the functional role of lncRNA SNHG20 in glioblastoma remains unclear. Therefore, we investigated the role of SNHG20 in glioblastoma. In this study, SNHG20 was highly expressed in glioblastoma tissues and cell lines and closely related to unfavorable prognosis of glioblastoma patients. Thus, we hypothesized the involvement of SNHG20 in the tumorigenesis and progression of glioblastoma. Functionally, MTT assay and colony formation assay revealed that 

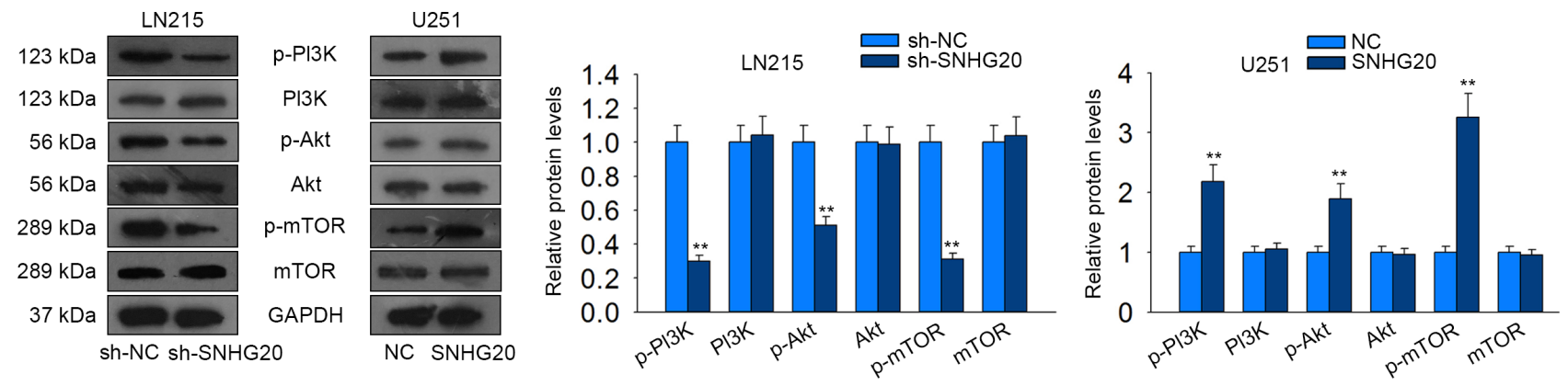

Figure 6. SNHG20 positively regulated the activity of PI3K/Akt/mTOR signaling pathway. Western blotting was carried out to detect the protein level of mTOR/p-mTOR, PI3K/p-PI3K, and AKT/p-AKT in LN215 and U251 cells after transfections. GAPDH was utilized as internal control. ${ }^{\star *} \mathrm{p}<0.01$.
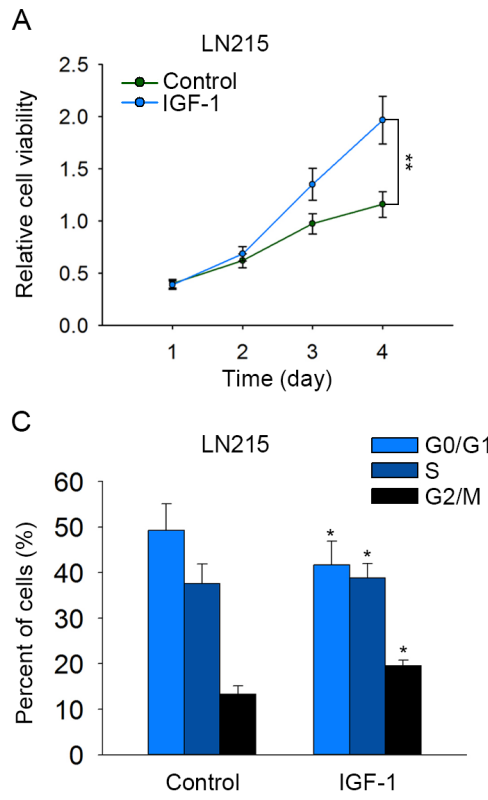

$\mathrm{E}$

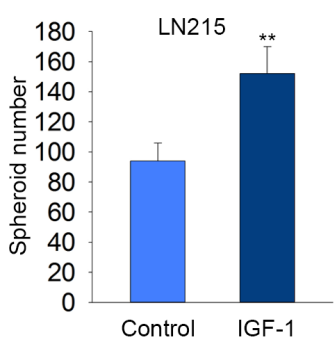

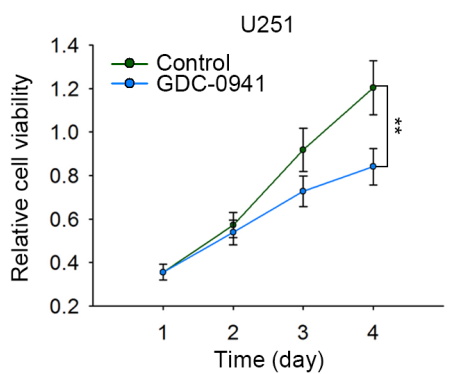

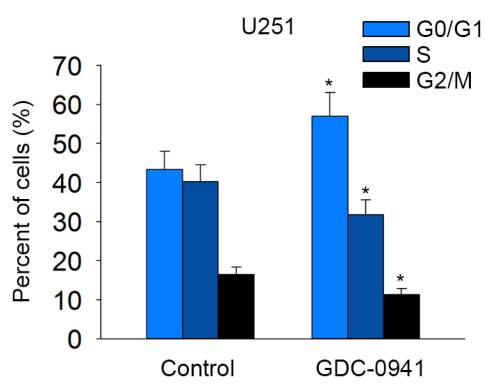

B
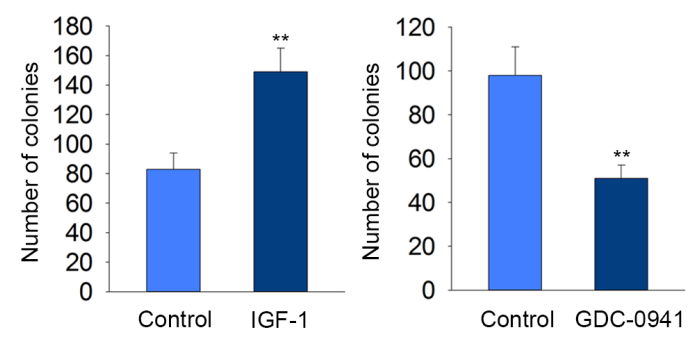

D

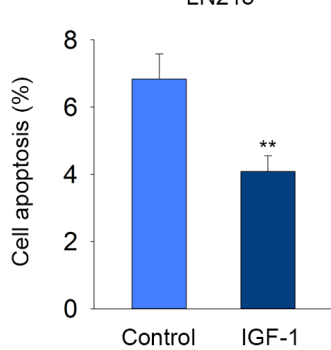

U251

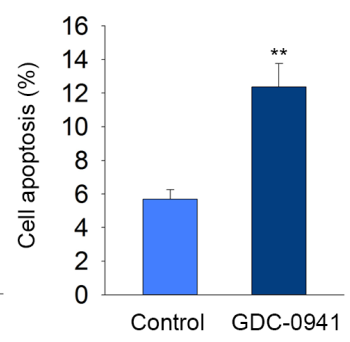

$\mathrm{F}$
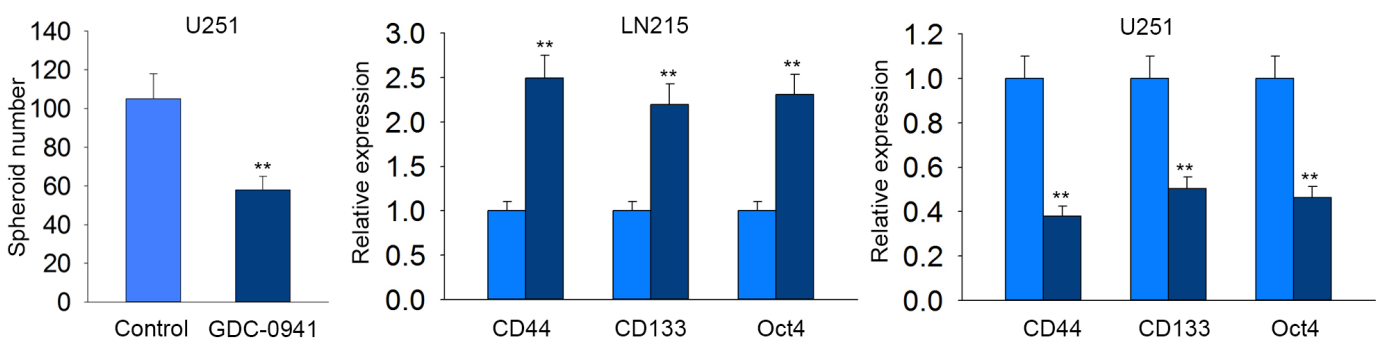

Figure 7. PI3K/Akt/mTOR signaling pathway promoted cell proliferation and enhanced stemness in glioblastoma. A-B) Cell proliferation was detected in LN215 cells treated with IGF-1 (PI3K signaling activator) or U251 cells treated with GDC-0941 (PI3K signaling inhibitor). C-D) Cell cycle distribution and apoptosis were assessed in LN215 cells treated with IGF-1 or U251 cells treated with GDC-0941. E) The sphere formation was evaluated in LN215 cells treated with IGF- 1 or U251 cells treated with GDC-0941. F) The expression levels of CD33, CD133 and Oct-4 were examined in LN215 cells treated with IGF-1 or U251 cells treated with GDC-0941. ${ }^{*} \mathrm{p}<0.05,{ }^{* *} \mathrm{p}<0.01$.

SNHG20 promoted cell proliferation in glioblastoma. Cell proliferation is usually accompanied with the changes of cell cycle progress and apoptosis [25-27]. Therefore, we further detected whether SNHG20 affected cell cycle distri- bution and apoptosis. According to the results from flow cytometry analysis, we identified that SNHG20 promoted cell cycle progress and inhibited cell apoptosis in glioblastoma. Consistently, the levels of proteins associated with 
A

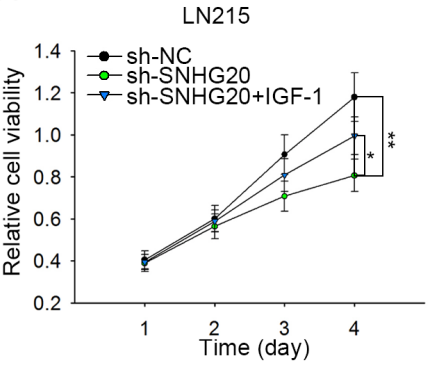

C
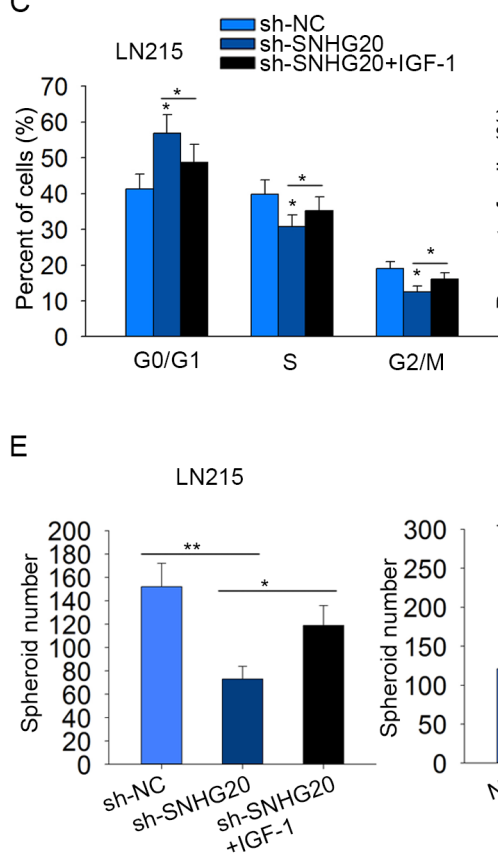
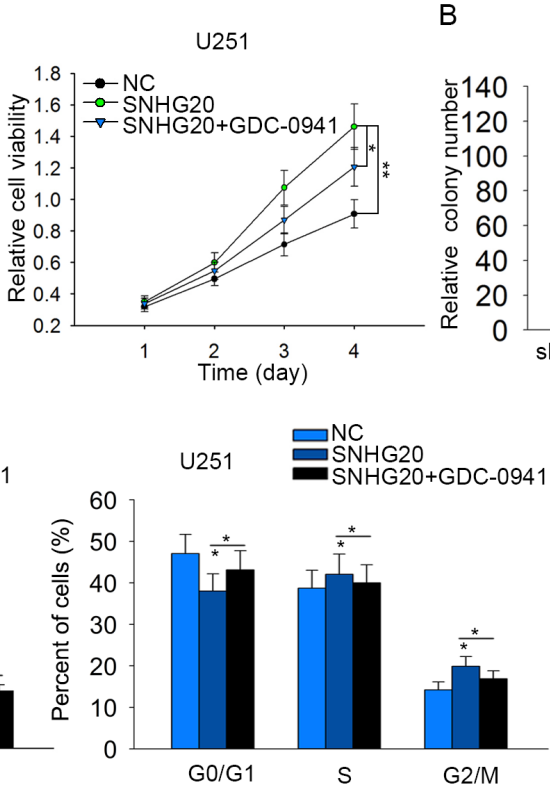

B

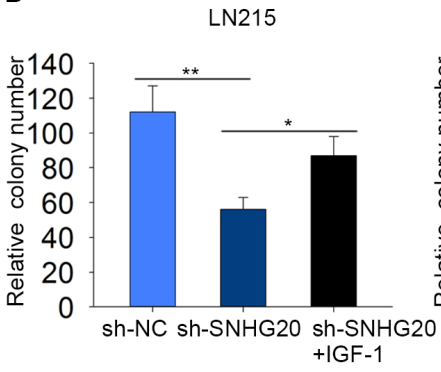

D
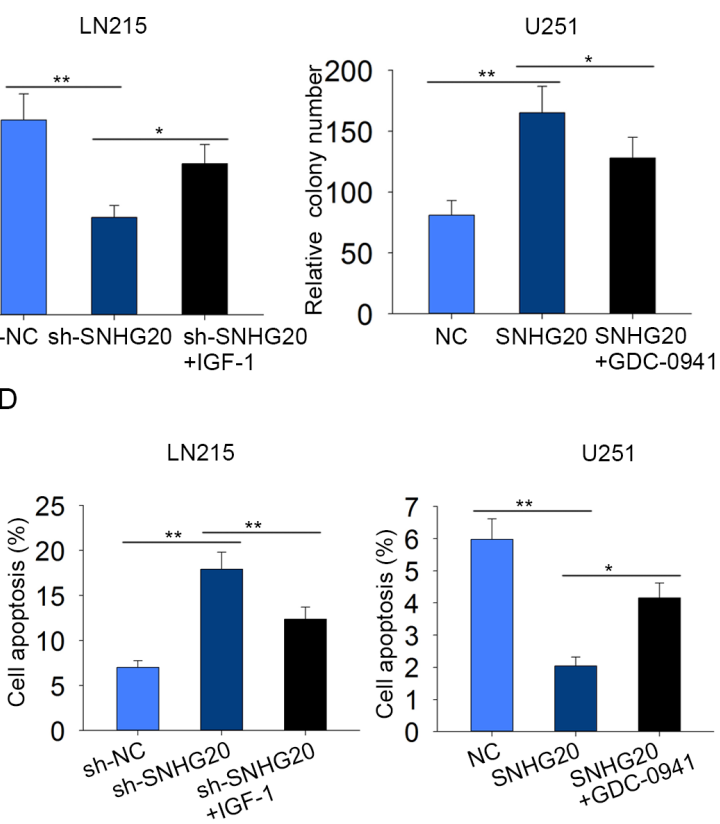

$\mathrm{F}$
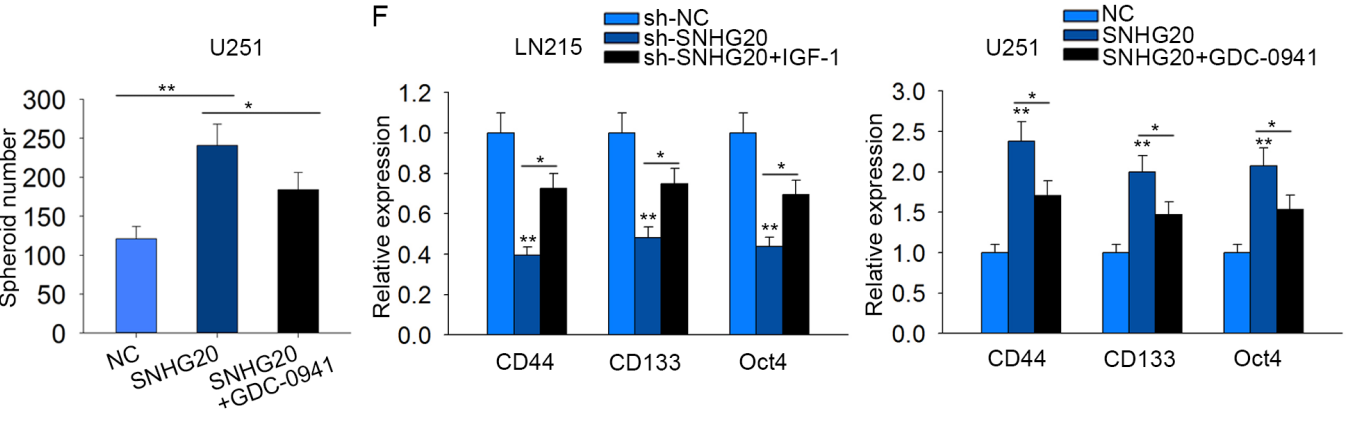

Figure 8. SNHG20 promoted tumorigenesis and cancer stemness in glioblastoma via activating PI3K/Akt/mTOR signaling pathway. A-B) Cell proliferation was analyzed in LN215 cells treated with sh-SNHG20 and IGF-1 and in U251 cells treated with SNHG20 and GDC-0941. C-D) Cell cycle distribution and apoptosis in indicated LN215 and U251 cells were detected by flow cytometry assay. E-F) The stemness of glioblastoma cells was investigated by sphere formation assay and $\mathrm{qRT}-\mathrm{PCR}$ assay. ${ }^{\star} \mathrm{p}<0.05,{ }^{\star *} \mathrm{p}<0.01$.

cell cycle and apoptosis were regulated by SNHG20, further validated the effects of SNHG20 on cell cycle progress and cell apoptosis. In vivo experiment further verified that SNHG20 promoted tumor growth in glioblastoma. Accumulating evidences indicate that the existence of cancer stem cells is correlated with cell proliferation, migration and self-renewal [28-30]. Thus, we further investigated the potential of SNHG20 to regulate stemness in glioblastoma. Interestingly, SNHG20 promoted sphere formation and increased the expression levels of stemness-associated genes. These results suggested that SNHG20 acted as an oncogene in glioblastoma by regulating cell proliferation, apoptosis and stemness.

The PI3K/Akt/mTOR signaling pathway has been reported to exert vital function in cell proliferation, differentiation, migration and invasion [31,32]. In our present study, we explored the correlation between SNHG20 and
PI3K/Akt/mTOR signaling. SNHG20 enhanced the levels of p-PI3K, p-Akt and p-mTOR, suggesting that SNHG20 potentially activated PI3K/Akt/mTOR signaling. Furthermore, glioblastoma cells were treated with an inhibitor or an activator of PI3K signaling. Functional assays suggested that the positive effect of PI3K/Akt/mTOR signaling on the tumorigenesis and stemness of glioblastoma. Finally, rescue assays showed that the inhibitor of activator reversed the cell proliferation, apoptosis and stemness mediated by SNHG20 overexpression or knockdown. These findings indicated that PI3K/Akt/mTOR signaling involved in SNHG20mediated glioblastoma cellular progression. Based on our findings, we confirmed that SNHG20 promoted tumorigenesis and cancer stemness in glioblastoma via activating $\mathrm{PI} 3 \mathrm{~K} / \mathrm{Akt} / \mathrm{mTOR}$ signaling pathway. Therefore, SNHG20 may be considered as a novel potential therapeutic target for glioblastoma. 


\section{References}

[1] ROCK K, MCARDLE O, FORDE P, DUNNE M, FITZPATRICK D et al. A clinical review of treatment outcomes in glioblastoma multiforme--the validation in a non-trial population of the results of a randomised Phase III clinical trial: has a more radical approach improved survival? Br J Radiol 2012; 85: e729-733. https://doi.org/10.1259/ bjr/83796755

[2] JOVCEVSKA I, KOCEVAR N, KOMEL R. Glioma and glioblastoma - how much do we (not) know? Mol Clin Oncol 2013; 1: 935-941. https://doi.org/10.3892/mco.2013.172

[3] BRENNAN CW, VERHAAK RG, MCKENNA A, CAMPOS B, NOUSHMEHR $\mathrm{H}$ et al. The somatic genomic landscape of glioblastoma. Cell 2013; 155: 462-477. https://doi. org/10.1016/j.cell.2013.09.034

[4] LOUIS DN, PERRY A, REIFENBERGER G, VON DEIMLING A, FIGARELLA-BRANGER D et al. The 2016 World Health Organization Classification of Tumors of the Central Nervous System: a summary. Acta Neuropathol 2016; 131: 803-820. https://doi.org/10.1007/s00401-016-1545-1

[5] ZHUANG ST, CAI YJ, GAO HC, QIU JF, ZENG L et al. Study on the function and mechanism of long non-coding RNA DMTF1v4 in the occurrence of colon cancer. Eur Rev Med Pharmacol Sci 2018; 22: 3779-3788. https://doi. org/10.26355/eurrev_201806_15260

[6] POSTEPSKA-IGIELSKA A, GIWOJNA A, GASRI-PLOTNITSKY L, SCHMITT N, DOLD A et al. LncRNA Khps1 Regulates Expression of the Proto-oncogene SPHK1 via Triplex-Mediated Changes in Chromatin Structure. Mol Cell 2015; 60: 626-636. https://doi.org/10.1016/j.molcel.2015.10.001

[7] GONZALEZ I, MUNiTA R, AGIRRE E, DITTMER TA, GYSLING $\mathrm{K}$ et al. A lncRNA regulates alternative splicing via establishment of a splicing-specific chromatin signature. Nat Struct Mol Biol 2015; 22: 370-376. https://doi. org/10.1038/nsmb.3005

[8] GONG C, MAQUAT LE. IncRNAs transactivate STAU1-mediated mRNA decay by duplexing with 3' UTRs via Alu elements. Nature 2011; 470: 284-288. https://doi.org/10.1038/ nature09701

[9] ZHANG L, WANG Q, WANG F, ZHANG X, ZHANG L et al. LncRNA LINC01446 promotes glioblastoma progression by modulating miR-489-3p/TPT1 axis. Biochem Biophys Res Commun 2018; 503: 1484-1490. https://doi.org/10.1016/j. bbrc.2018.07.067

[10] ZHOU Y, DAI W, WANG H, PAN H, WANG Q. Long noncoding RNA CASP5 promotes the malignant phenotypes of human glioblastoma multiforme. Biochem Biophys Res Commun 2018; 500: 966-972. https://doi.org/10.1016/j. bbrc.2018.04.217

[11] CHEN Q, CAI J, WANG Q, WANG Y, LIU M et al. Long Noncoding RNA NEAT1, Regulated by the EGFR Pathway, Contributes to Glioblastoma Progression Through the WNT/beta-Catenin Pathway by Scaffolding EZH2. Clin Cancer Res 2018; 24: 684-695. https://doi.org/10.1158/10780432.CCR-17-0605
[12] YAO Y, MA J, XUE Y, WANG P, LI Z et al. Knockdown of long non-coding RNA XIST exerts tumor-suppressive functions in human glioblastoma stem cells by up-regulating miR-152. Cancer Lett 2015; 359: 75-86. https://doi. org/10.1016/j.canlet.2014.12.051

[13] GUAN YX, ZHANG MZ, CHEN XZ, ZHANG Q, LIU SZ et al. Lnc RNA SNHG20 participated in proliferation, invasion, and migration of breast cancer cells via miR-495. J Cell Biochem 2018; 119: 7971-7981. https://doi.org/10.1002/ jcb. 26588

[14] GUO H, YANG S, LI S, YAN M, LI L et al. LncRNA SNHG20 promotes cell proliferation and invasion via miR140-5p-ADAM10 axis in cervical cancer. Biomed Pharmacother 2018; 102: 749-757. https://doi.org/10.1016/j.biopha.2018.03.024

[15] LI C, ZHOU L, HE J, FANG XQ, ZHU SW et al. Increased long noncoding RNA SNHG20 predicts poor prognosis in colorectal cancer. BMC Cancer 2016; 16: 655. https://doi. org/10.1186/s12885-016-2719-x

[16] BRODIE S, LEE HK, JIANG W, CAZACU S, XIANG C et al. The novel long non-coding RNA TALNEC2, regulates tumor cell growth and the stemness and radiation response of glioma stem cells. Oncotarget 2017; 8: 31785-312801. https:// doi.org/10.18632/oncotarget.15991

[17] ZHANG Y, ZHANG R, LUO G, AI K. Long noncoding RNA SNHG1 promotes cell proliferation through PI3K/AKT signaling pathway in pancreatic ductal adenocarcinoma. J Cancer 2018; 9: 2713-2722. https://doi.org/10.7150/jca.26207

[18] LIU G, ZHAO X, ZHOU J, CHENG X, YE Z et al. LncRNA TP73-AS1 Promotes Cell Proliferation and Inhibits Cell Apoptosis in Clear Cell Renal Cell Carcinoma Through Repressing KISS1 Expression and Inactivation of PI3K/Akt/ mTOR Signaling Pathway. Cell Physiol Biochem 2018; 48: 371-384. https://doi.org/10.1159/000491767

[19] HUANG Y, ZHANG J, HOU L, WANG G, LIU H et al. LncRNA AK023391 promotes tumorigenesis and invasion of gastric cancer through activation of the PI3K/Akt signaling pathway. J Exp Clin Cancer Res 2017; 36: 194. https://doi. org/10.1186/s13046-017-0666-2

[20] MA S, YANG D, LIU Y, WANG Y, LIN T et al. LncRNA BANCR promotes tumorigenesis and enhances adriamycin resistance in colorectal cancer. Aging (Albany NY) 2018; 10: 2062-2078. https://doi.org/10.18632/aging.101530

[21] BATISTA PJ, CHANG HY. Long noncoding RNAs: cellular address codes in development and disease. Cell 2013; 152: 1298-1307. https://doi.org/10.1016/j.cell.2013.02.012

[22] RINN JL, CHANG HY. Genome regulation by long noncoding RNAs. Annu Rev Biochem 2012; 81: 145-166. https:// doi.org/10.1146/annurev-biochem-051410-092902

[23] ZHOU X, REN Y, ZHANG J, ZHANG C, ZHANG K et al. HOTAIR is a therapeutic target in glioblastoma. Oncotarget 2015; 6: 8353-8365. https://doi.org/10.18632/oncotarget.3229

[24] WANG Y, WANG Y, LI J, ZHANG Y, YIN H et al. CRNDE, a long-noncoding RNA, promotes glioma cell growth and invasion through mTOR signaling. Cancer Lett 2015; 367: 122-128. https://doi.org/10.1016/j.canlet.2015.03.027 
[25] LIU Y, LIN L, ZOU R, WEN C, WANG Z et al. MSC-derived exosomes promote proliferation and inhibit apoptosis of chondrocytes via lncRNA-KLF3-AS1/miR-206/GIT1 axis in osteoarthritis. Cell Cycle 2018; 17: 2411-2422. https://doi. org/10.1080/15384101.2018.1526603

[26] WANG J, PU J, ZHANG Y, YAO T, LUO Z et al. DANCR contributed to hepatocellular carcinoma malignancy via sponging miR-216a-5p and modulating KLF12. J Cell Physiol 2019; 234: 9408-9416. https://doi.org/10.1002/jcp.27625

[27] ZHAO X, CHENG Z, WANG J. Long Noncoding RNA FEZF1-AS1 Promotes Proliferation and Inhibits Apoptosis in Ovarian Cancer by Activation of JAK-STAT3 Pathway. Med Sci Monit 2018; 24: 8088-8095. https://doi.org/10.12659/ MSM.911194

[28] REYA T, MORRISON SJ, CLARKE MF, WEISSMAN IL. Stem cells, cancer, and cancer stem cells. Nature 2001; 414: 105-111. https://doi.org/10.1038/35102167
[29] BRETT EA, AITZETMULLER MM, SAUTER MA, HUEMER GM, MACHENS HG et al. Breast cancer recurrence after reconstruction: know thine enemy. Oncotarget 2018; 9: 27895-27906. https://doi.org/10.18632/oncotarget.25602

[30] ZHAO W, ZHANG X, ZANG L, ZHAO P, CHEN Y et al. ILK promotes angiogenic activity of mesenchymal stem cells in multiple myeloma. Oncol Lett 2018; 16: 1101-1106. https://doi.org/10.3892/ol.2018.8711

[31] ZHAI C, CHENG J, MUJAHID H, WANG H, KONG J et al. Selective inhibition of PI3K/Akt/mTOR signaling pathway regulates autophagy of macrophage and vulnerability of atherosclerotic plaque. PLoS One 2014; 9: e90563. https://doi. org/10.1371/journal.pone.0090563

[32] Zhang H, Xu HL, Wang YC, Lu ZY, Yu XF et al. 20(S)-Protopanaxadiol-Induced Apoptosis in MCF-7 Breast Cancer Cell Line through the Inhibition of PI3K/AKT/mTOR Signaling Pathway. Int J Mol Sci 2018; 19. https://doi.org/10.3390/ ijms 19041053 